\title{
Design and Analysis of Figure Eight Shaped Slot Antenna Array for Wideband Applications
}

\author{
A.Srilakshmi, N.V.Koteswara Rao, D.Sreenivasa Rao
}

\begin{abstract}
An eight shaped annular ring slot antenna array is presented. Feed is designed with $T$ shaped Power divider and quarterwave transformer is used. Antenna element is comprised of two linked annular slots to achieve high band width. Analysis is carried out with HFSS simulation software. Array is configured with corporate feed structure. It has been observed tha gain is increased to $4 d B$ to $5 d B$ and return loss band width increased from $600 \mathrm{MHz}$ to $1.2 \mathrm{GHz}$ around 55\%, Cross polarization level also significantly decreased,
\end{abstract}

Keywords: Microstrip Antenna, Wideband, Annular Ring Slot antenna array

\section{INTRODUCTION}

$\mathrm{I}_{\mathrm{t}}$ $t$ is well known that annular ring patch antennas [1-5] and annular slot antennas[6-9] have bring interest because of their significant characteristics such as wide bandwidth, small size, light weight and ease of fabrication.

Normally the bandwidth for single frequency annular slot is about $10 \%[6,9]$. Several techniques have been reported to achieve broad band for annular slot antennas[9,10]. It has been reported in the subsequent work [11-14], annular slot antenna have $10-20 \%$ impedance bandwidth, which is wider than conventional microstrip patch antenna.

However the development of wireless communications experiencing an exponential growth hence increase the need for wideband microstrip antennas. As a result, new antennas have to developed to provide larger bandwidth and this, within small dimensions. challenge which arises is that the gain and bandwidth performances of an antenna are directly related to its dimensions. These applications include WWANs, WLANs and WPANs. Usually, broad band characteristics are tough to achieve, because good impedance matching is difficult. In this paper an 8- shaped slot antenna is proposed, there by increasing the surface current path and enabling wide bandwidth of the slot antenna. By adjusting the parameters of the antenna parametric analysis is carried out using HFSS software by changing the inclination angle that is angle between the line joining centers of two circles of figure eight and a vertical reference line. The optimized results are found to be impedance bandwidth more than $1 \mathrm{GHz}$. A simple $50 \mathrm{ohms}$ microstrip line is used to excite the slot.

Revised Manuscript Received on July 22, 2019.

* Correspondence Author

A.Srilakshmi *, Associate Professor, Vasari college of Engineering, ECE department, Hyderabad, India,srilakshmi08@yahoo.com

N.V.Koteswara Rao, Professor of ECE, CBIT, Hyderabad, India, nvkoteswararao@gmail.com

D.Sreenivasa Rao, Professor of ECE, JNTUH,Hyderabad, India, dsrao@yahoo.co.uk
Annular slot antennas have relatively broad band characteristics compare to conventional patch antennas. Normally, for narrow slot antennas impedance bandwidth is around $10 \%$. However for wide slots high bandwidth can be obtained, because of reduced quality factor. A single layer with 8 shaped slot is taken out of infinite ground plane. FR4 substrate was selected to reduce the cost, which has a relative permittivity of 4.4 , loss tangent of 0.01 and a thickness of $1.56 \mathrm{~mm}$. Single element ground plane and substrate sizes are $65 \mathrm{mmX} 35 \mathrm{~mm}$. Radius of inner ring of the slot is $\mathrm{Ri}=6.5 \mathrm{~mm}$, Radius of the outer ring slot is taken as $\mathrm{Ro}=9.5 \mathrm{~mm}$. Parametric Analysis is carried out with combinations of the angle between the line joining the centers of the two rings of eight shaped slot and a vertical reference line from 15 to 90 degrees in steps of 15 degrees and with permutations of the distance between the centers of the two rings of eight shaped slot from $7 \mathrm{~mm}$ to $9.5 \mathrm{~mm}$ in steps of $0.5 \mathrm{~mm}$. single element is designed with the Size $35 \mathrm{~mm} \times 65 \mathrm{~mm} \times 1.6 \mathrm{~mm}$. Its optimal impedance band width $\left(\mathrm{S}_{11}<-10 \mathrm{~dB}\right)$ is 2.12 to $3.16 \mathrm{GHz}$, more than $1 \mathrm{GHz}$, $44 \%$ centered at $2.3 \mathrm{GHz}$ at angle of rotation is 15 degrees and centre to centre distance $17 \mathrm{~mm}$.. The 50 ohms feed line length is $\mathrm{fl}=19.5 \mathrm{~mm}$, and width is fw3mm was designed for good impedance matching. Angle of inclination AG is varied from 15 to 90 degrees insteps of 15 degrees. The half of the distance between the centers of two linked annular rings is $R_{c}$ is varied from 7 to $9.5 \mathrm{~mm}$ insteps of $0.5 \mathrm{~mm}$. Only one parameter is varied every time in the numerical simulation The simulated and measured results are explained below.

\section{CONFIGURATION AND DESIGN OF EIGHT SHAPED ANNULAR RING SLOT ANTENNA}

The configuration of figure eight shaped annular ring slot antenna is illustrated in figure1. It consists of eight shaped annular slot. The slot antenna is excited by a 50 ohms microstrip line to provide impedance matching. Normally the resonant frequencies are mainly found by circumference length of annular slot. The annular- slot width and the microstrip feed line parameters have significant effect on antenna parameters. The fundamental resonant frequency of conventional annular circular ring slot antenna comprises in the ground plane of a dielectric substrate fed by a microstrip conductor can be calculated according to the following[12] $f_{0}=\frac{300}{2 \pi R_{m} \sqrt{\varepsilon_{r e}}}$------------- 1

Where $R_{m}$ is the average radius of inner ring radius and outer ring radius in $\mathrm{mm}$. $\mathrm{f}_{0}$ is the resonant frequency in $\mathrm{GHz}$. And $\varepsilon_{r e}$ is effective dielectric constant of annular ring patch is given by

$$
\varepsilon_{r e}=\frac{2 \varepsilon_{r}}{1+\varepsilon_{r}}
$$




\section{Design and Analysis of Figure Eight shaped slot antenna array for wideband applications}

To improve the impedance bandwidth one more annular linked slot is introduced. Using below equation width of the microstrip line width for $50 \mathrm{ohms}$ is calculated[15].

$$
Z_{0}(\Omega)=\frac{87}{\sqrt{\varepsilon_{r}+1.41}} \ln \left[\frac{5.98 h}{(0.8 w+t)}\right] \quad----3
$$

The first mode is mainly determined by the circumference of the inner and outer slot rings (in case of the multiple rings), and the second mode is mainly determined by the outer circumference.

The angular-slot widths and the micro-strip feed line parameters also have significant effect on the performance. This is given by

$$
\lambda_{g s=} 2 \pi R^{-------------------------------------------------------------4}
$$

Where $R$ is the radius of the angular-ring slot, $\lambda_{g s}$ is the slot guided wavelength

$\lambda_{g s}=\lambda_{0}\left\{(1.045-0.365) \ln \varepsilon_{r}+\frac{6.3\left(\frac{W}{h}\right) \varepsilon_{r}^{0.945}}{(238.64+100 W / h}-[0.148-\right.$ $\left.\frac{8.81\left(\varepsilon_{r}+0.95\right)}{100 \varepsilon r}\right] \ln \left(\frac{h}{\lambda_{0}}\right)$

For a single ring, when the mean circumference of the ring is equal to an integral multiple of the guided wavelength, the resonance is expressed as the

$\mathrm{I}=2 \pi \mathrm{R}=\mathrm{n} \lambda_{g s}$ for $\mathrm{n}=1,2,3, \ldots \ldots$

Where $I$ is the mean circumference of the ring,

I. $\lambda_{g s}=\frac{\lambda_{0}}{\sqrt{\varepsilon_{e f f}}}$

The resonant frequencies can be represented as:

$f_{n}=\frac{n c}{l \sqrt{\varepsilon_{\text {eff }}}}$

For mode $n=1,2,3 \ldots$ where $\mathrm{c}$ is the speed of the light.

Calculations:

Resonant Frequency without fringing effect) for the $T M_{11}$ mode is given by

$f_{r}=\frac{1.8412 c}{2 \pi a \sqrt{\varepsilon_{r}}}$

Resonant Frequency (with fringing effect) is given as

$$
f_{r}=\frac{1.8412 c}{2 \pi a_{e} \sqrt{\varepsilon_{r}}}
$$

The effective radius $a_{e}$ is used in the place of the actual radius (due to fringing effect)

$a_{e}$

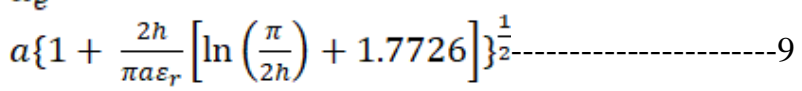

The design of the circular and slot of the angular ring shape is

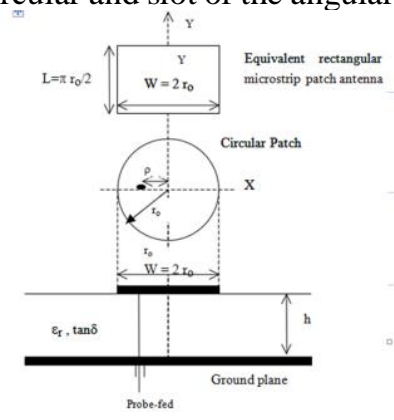

Fig: 1A Circular patch antenna and its equivalent rectangular patch antenna on thick substrate.

For the equivalent rectangular patch of width $\mathrm{W}=2 \mathrm{r}_{\mathrm{o}}$, the length $\mathrm{L}=(\boldsymbol{\pi} / 2) \mathrm{r}_{\mathrm{o}}$ is obtained by using the invariance of electrostatic energy below both the rectangular and circular patches.

\section{ANALYSIS AND STUDY OF THE PARAMETERS}

Design-1:

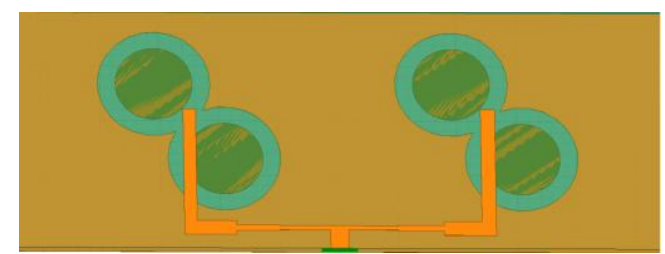

Fig1.1: Structure of two element antenna array - design 1

Figure 1.1 shows the structure of two element antenna array with T Junction feed with impedance matching of $50 \Omega$. The $\mathrm{T}$ junction is made with $50 \Omega$ line and two $100 \Omega$ line connecting next to it proceeded by the quarter wave transformer and again the $50 \Omega$ feed line to the patch is connected.

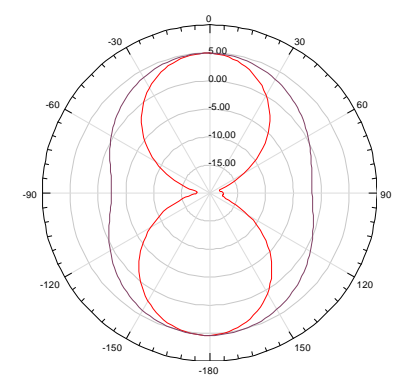

Figure 1.2 Radiation Pattern of design-1

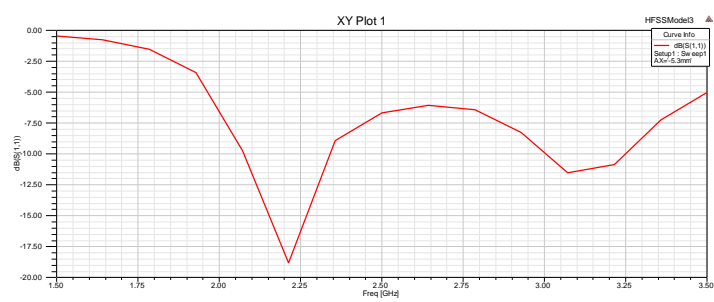

Figure 4.5 Return loss vs frequency (design-1)

From the radiation pattern and reflection coefficient it is clear that the gain with this particular feed is $5 \mathrm{~dB}$ and the bandwidth obtained is $200 \mathrm{MHz}$. It is observed that Radiation pattern is symmetric.

.Design-2:

Figure 2.1 shows that the structure of four element antenna array with corporate feed. This feed consists of different lines with impedances $50 \Omega, 100 \Omega$ and $70.7 \Omega$ to get input impedance as $50 \mathrm{ohm}$ for each element. The feed is arranged in such a way like quarter wave transformer (70.7) is present in between two different impedances.

The center to center gap between the two patches is $65 \mathrm{~mm}$. 


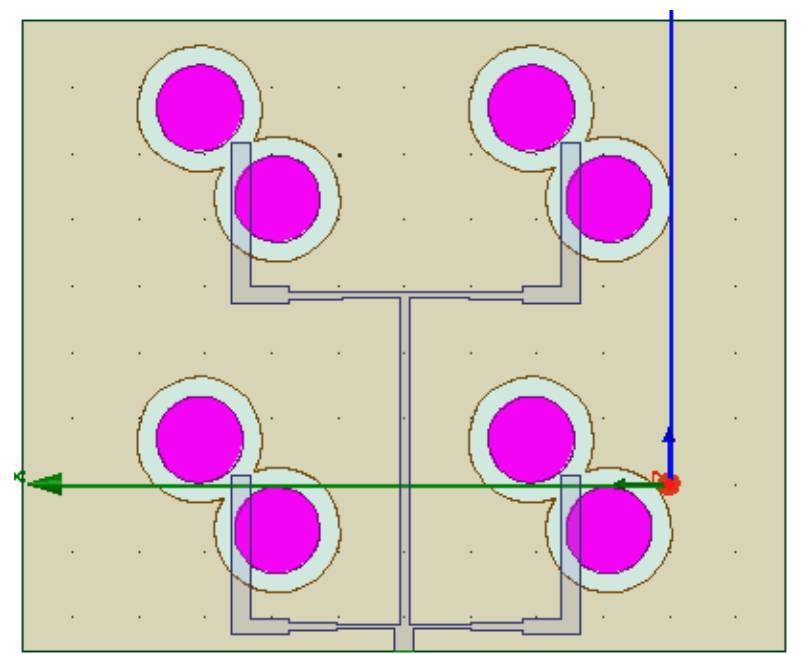

Figure 2.1Geometrical structure of design-2

From the fig 2.2 and fig 2.3, the radiation pattern and reflection coefficient, it is clear that the maximum gain is $2.5 \mathrm{~dB}$ and $180 \mathrm{MHz}$ of bandwidth respectively.

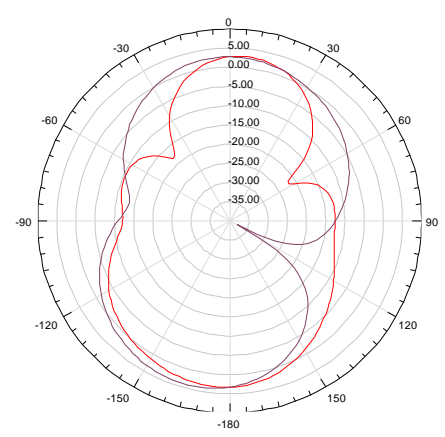

Figure 2.2 Radiation pattern of design-2

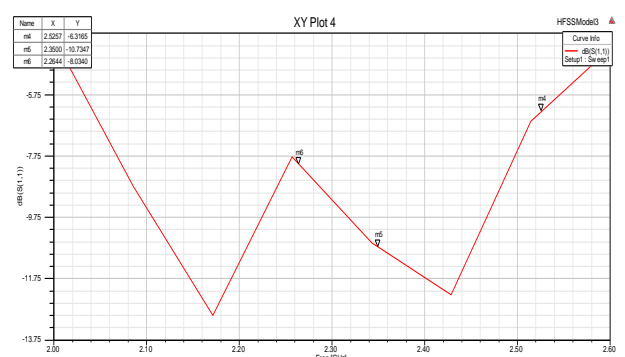

Figure 2.3 Reflection coefficientof design-2

Design-3:

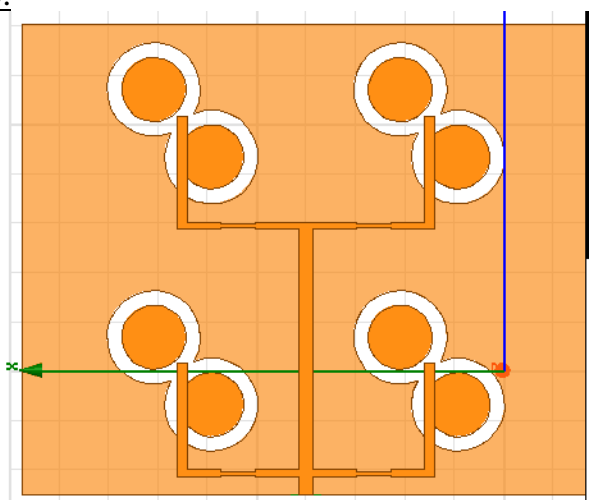

Figure 3.1 Geometrical structure of design-3
Figure 3.1 represents the modified with center to center gap between two patches is $50 \mathrm{~mm}$.It is observed that the center to center gap between the patches has main role in the improvement of gain and bandwidth.

Thus the center to center gap is changed in both vertical and horizontal directions which has good bandwidth and gain.

From the fig 3.2 and fig 3.3, radiation pattern and reflection coefficient, it is clear that the gain of appro. $5.5 \mathrm{~dB}$ and $630 \mathrm{MHz}$ of bandwidth respectively.

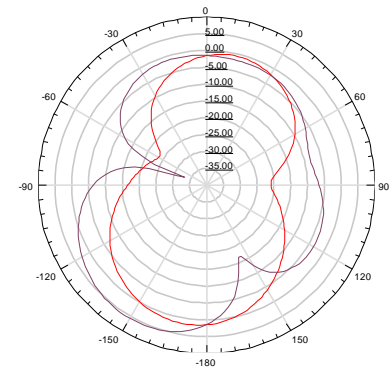

Figure 3.2 Radiation Pattern of design-3

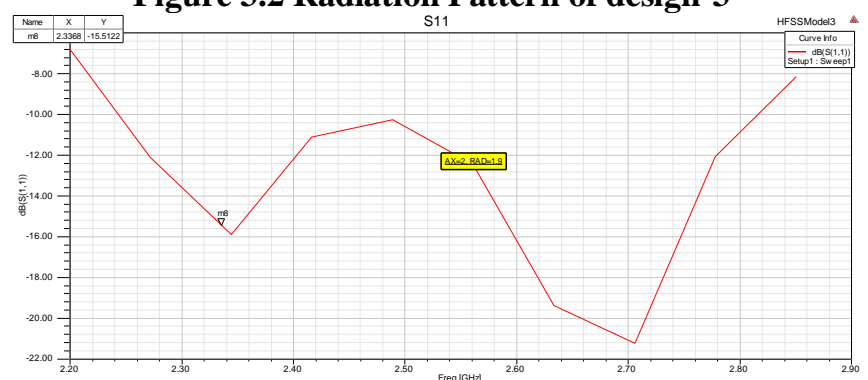

Figure 3.3 Reflection coefficient of design-3

Design-4:

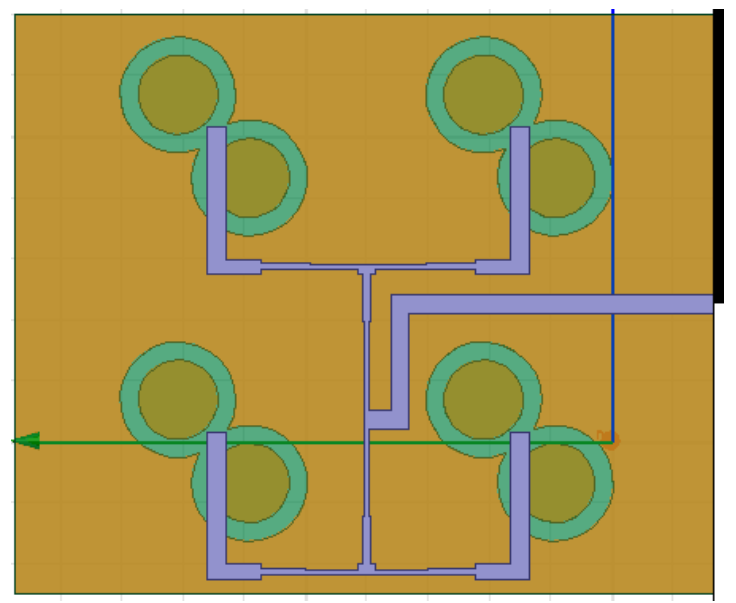

Figure 4.1Geometrical structure of design-4

Figure 4.1 describes $2 \mathrm{X} 2$ array with Feed system consisting of $3 \mathrm{~T}$-junctions and a $\mathrm{L}$ shaped bend where there is no change in the resistance along the path. Quarter wave transformer is placed on either side of the 100ohm line in order to get maximum power transfer. After 100ohm line another $50 \mathrm{ohm}$ feed line with a quarter wave transformer is used.From the Fig 4.2 and Fig 4.3 radiation pattern and Returnloss characteristics gain is $5 \mathrm{~dB}$ returnloss bandwidth obtained is $680 \mathrm{MHz}$. Radiation pattern is symmetric 


\section{Design and Analysis of Figure Eight shaped slot antenna array for wideband applications}

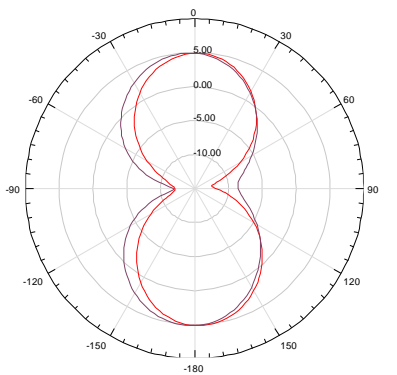

Figure 4.22Radiation Pattern of design-8

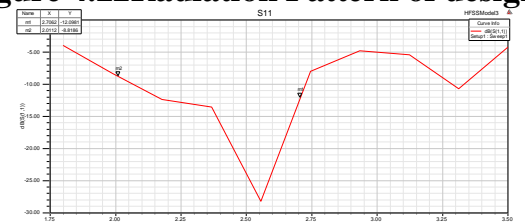

Figure 4.23 Reflection coefficient of design-8

\section{Design-5:}

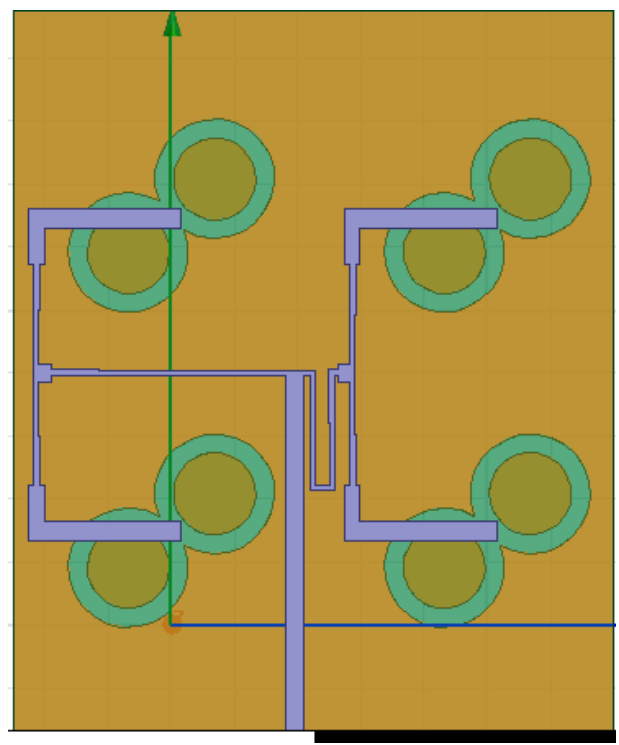

Figure 5.1 Geometrical structure of design-5

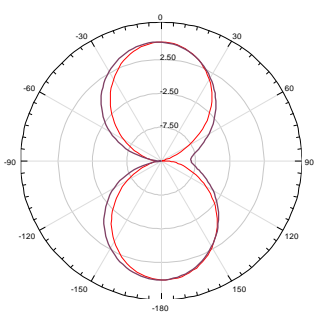

Figure 5.2 Radiation pattern of design-5

Feed network is designed such a way that, the length of $\mathrm{T}$-junction feed is symmetrical and length of the $\mathrm{T}$ junction arms is different i.e., it From the radiation pattern and reflection coefficient it is clear that the gain with this particular feed is $5 \mathrm{~dB}$ and the bandwidth obtained is 300MHz.

Radiation pattern is symmetric because its geometrical structure is in a symmetric fashion. The figures 5.2,5.3 shows the radiation pattern and Return loss plot of the above antenna.

Design-6:

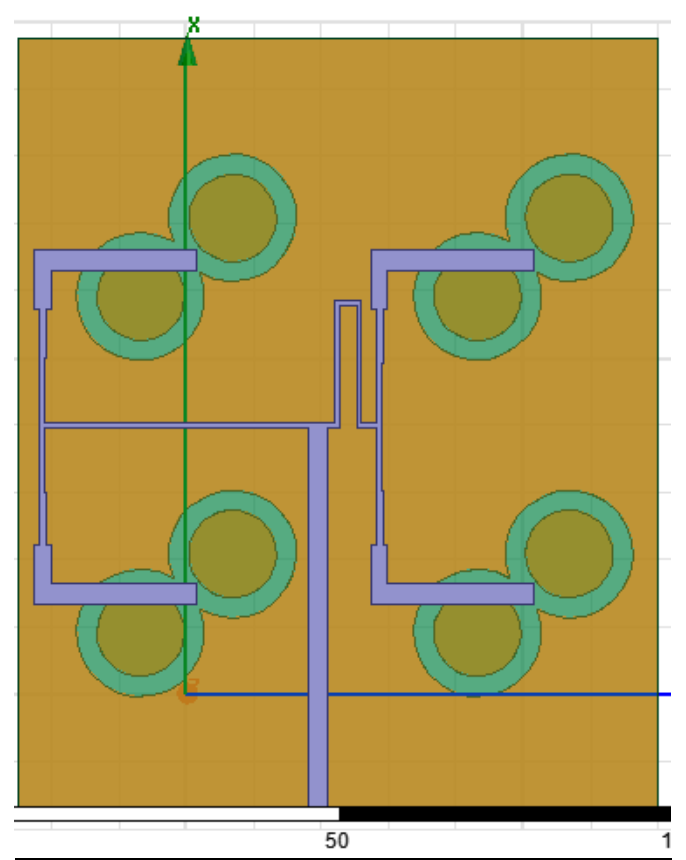

Description : This antenna is different from the antenna in Design 5 is the meander line is connected is in inverted fashion when compared to the fig 5 . Feed network is designed such a way that, the length of T-junction feed is symmetrical and length of the $\mathrm{T}$ junction arms is different i.e., it looks like meander shape on one side of $\mathrm{T}$ junction and after that QWT has been kept which is between the $100 \mathrm{ohm}$ and $50 \mathrm{ohm}$ line. There are total of two symmetrical $\mathrm{T}$ junctions in the above mentioned feed network. This meander shape in the above mentioned structure is in order to provide equal electrical length from the excitation feed. From the radiation pattern and reflection coefficient it is clear that the gain with this particular feed is $5 \mathrm{~dB}$ and the bandwidth obtained is $900 \mathrm{MHz}$.

Radiation pattern is symmetric because its geometrical structure is in a symmetric fashion.

Figure 5.1 Geometrical structure of design-5

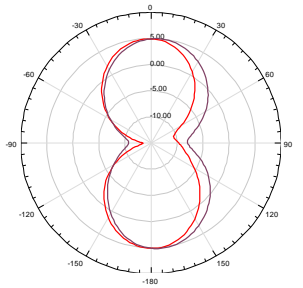

Figure 5.2 Radiation pattern of design-5

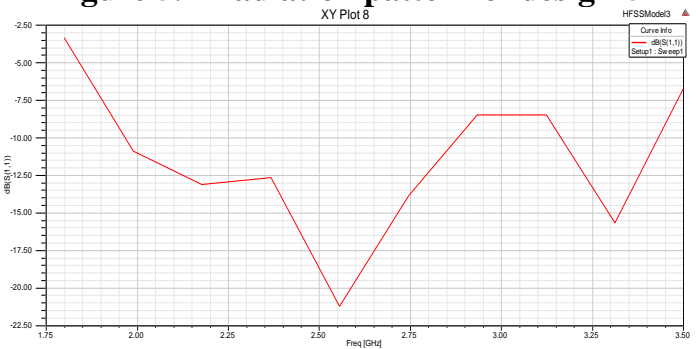

Figure 5.3 Returnloss characteristics of design 5

$\underline{\text { Design-7 }}$

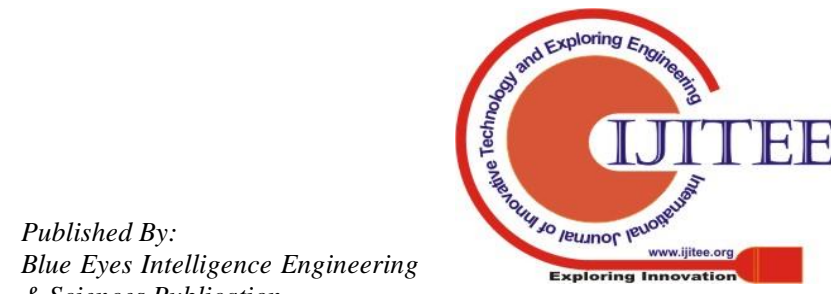




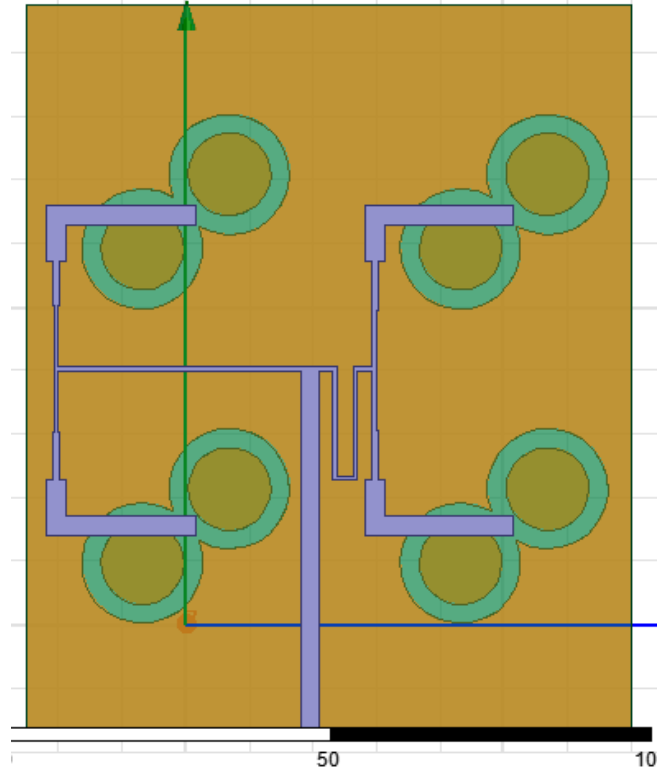

Figure 7.1 Geometrical structure of design-7

This antenna is different from the antenna in fig 8 is the meander line is connected is in inverted fashion when compared to the fig 8 .

Feed network is designed such a way that, the length of $\mathrm{T}$-junction feed is symmetrical and length of the $\mathrm{T}$ junction arms is different i.e., it looks like meander shape on one side of $\mathrm{T}$ junction and after that QWT has been kept which is between the $100 \mathrm{ohm}$ and $50 \mathrm{ohm}$ line.

There are total of two symmetrical $\mathrm{T}$ junctions in the above mentioned feed network. This meander shape in the above mentioned structure is in order to provide equal electrical length from the excitation feed

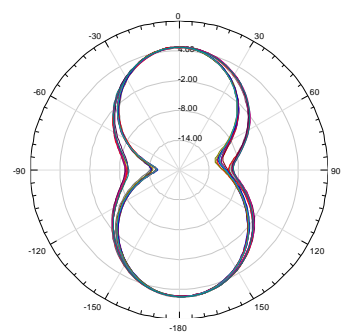

Figure 7.2 Radiation patternof design-7

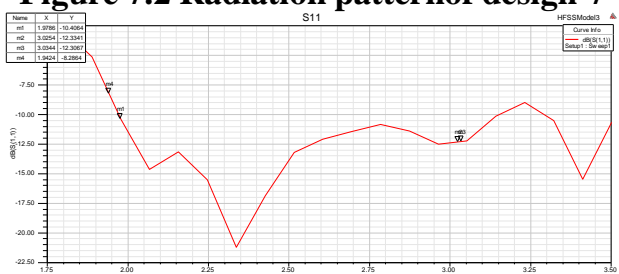

Figure 7.3 Returnloss design-7

\section{RESULTS AND DISCUSSIONS}

Based on the simulated results effect of angle of rotation and center to center distance of two annular slots of eight shaped slot are discussed in the following section. Number of elements are increased from single element to $2 \mathrm{X} 2$ array.

The Return loss plots by adjusting the rotation angle AG and distance of separation between the centers of rings $2 \mathrm{Rc}$ are shown in Figure.2. It is observed in figure. 2 that impedance bandwidth for return loss below $-10 \mathrm{~dB}$ is from $2.28 \mathrm{GHz}$ to $3.64 \mathrm{GHz}$ when angle of rotation $\mathrm{AG}=15$ degrees and $\mathrm{Rc}$ $=9 \mathrm{~mm}$, which is more than $44 \%$ centered at $2.3 \mathrm{GHz}$.
$\%$ Bandwidth for different combinations of antenna parameters is shown in figure 3. and in table1. Flatten gain of $4 \mathrm{dBi}$ is observed over the optimized band, shown in figure 4 . It is also observed that $\mathrm{E}$ plane and $\mathrm{H}$ plane Radiation patterns at different values of frequencies are relative omni directional shown in figure 5.

The impedance bandwidth of $2 \mathrm{X} 2$ array is $1.2 \mathrm{GHz}, 55 \%$ and gain is raised to $5 \mathrm{DB}$

Performance Comparison of arrays

\begin{tabular}{|l|l|l|l|}
\hline Parameter & Single element & $2 \mathrm{X} 1$ Array & $2 \mathrm{X} 2 \mathrm{Array}$ \\
\hline Co-Pol Gain & $4 \mathrm{~dB}$ & $5 \mathrm{~dB}$ & $5 \mathrm{~dB}$ \\
\hline Bandwidth & $600 \mathrm{MHz}$ & $400 \mathrm{MHz}$ & $1.2 \mathrm{GHz}$ \\
\hline Polarization & Circular & Circular & Circular \\
\hline X-Pol level & $-5 \mathrm{~dB}$ & $-5 \mathrm{~dB}$ & $-10 \mathrm{~dB}$ \\
\hline Axial ratio BW & $400 \mathrm{MHz}$ & $1 \mathrm{GHz}$ & $500 \mathrm{MHz}$ \\
\hline Area (ford in & $65 \times 35 \mathrm{~mm}^{2}$ & $44 \pi 115 \mathrm{~mm}^{2}$ & $95 \times 115 \mathrm{~mm}^{2}$ \\
\hline Complexity & Simple & Complex & Complex \\
\hline
\end{tabular}

\section{CONCLUSION}

An eight shaped annular ring slot antenna array is presented. Feed is designed with $\mathrm{T}$ shaped Power divider and quarter wave transformer is used. Antenna element is comprised of two linked annular slots to achieve high band width. Array is configured with corporate feed structure. It has been observed that gain is raised to $4 \mathrm{~dB}$ to $5 \mathrm{~dB}$ and return loss band width increased from $600 \mathrm{MHz}$ to $1.2 \mathrm{GHz}$, Cross polarization level also significantly decreased,

\section{REFERENCES}

1. Xiulong Bao, Max Amman,Microstrip-Fed Dual-Frequency Annular-Slot Antenna Loaded by Split-Ring-Slot,IET Microw. Antennas Propag., 2009, Vol. 3, Iss. 5, pp. 757-764

2. BATCHELOR J.C., LANGLEY R.J.: 'Microstrip ring antennas operating at higher order modes for mobile applications',IEE Proc. H, Microw., Antennas Propag., 1995, 141, (2),pp. 151-155

3. GUO Y.X., LUK K.M., LEE K.F.: 'L-probe proximity-fed annular ring microstrip antennas', IEEE Trans. Antennas Propag., 2001, 49, (1), pp. 19-21

4. BAO X.L., AMMANN M.J.: 'Comparison of several novel annular-ring microstrip patch antennas for circular polarization', J. Electromag. Waves Appl., 2006, 20, (11), pp. 1427-1438

5. Parsche, Fracis Eugene, US. Patent No. 6992630, Annulal ring Antenna

6. BATCHELOR J.C., LANGLEY R.J.: 'Microstrip annular ring slot antennas for mobile applicaiotns', Electron. Lett., 1996, 32, (18), pp. 1635-1636

7. SHARMA S.K., SHAFAI L., JACOB N.: 'Investigation of wideband microstrip slot antenna', IEEE Trans. Antennas Propag., 2004, 52, (3), pp. $865-872$

8. TEHRANI H., CHANG K.: 'Multifrequency operation of microstrip-fed slot-ring antennas on thin low-dielectric permittivity substrates, IEEE Trans. antennas Propag., 2002, 50, (9), pp. 1299-1308

9. YOSHIMURA Y.: 'A microstripline slot antenna', IEEE Trans. Microw. Theory Tech., 1972, 20, (11), pp. 760-762

10. HONG C.S.: 'Large bandwidth circular slot at resonance with directional radiation', Electron. Lett., 1988, 24, (23), pp. 1449-1450

11. JANG Y.W.: 'Experimental study of wideband printed annular slot antenna with cross-shaped feedline', Electron.Lett., 2002, 38, (22), pp. 1305-1307

12. T.-N. Chang,Wideband circularly polarised antenna using two linked annular slots, Electronics letters, June 2011 Vol. 47 No. 13

13. Chang, T.-N., and Han, Y.-L.: 'A dual-band circularly polarized antenna using combined C-shaped and L-shaped slots excited by a microstrip, Microwave and Optical Technology Letters, Volume 53 . 1041-1044, May 2011 
Design and Analysis of Figure Eight shaped slot antenna array for wideband applications

14. Balanis.C.A.Antenna Theory Analysis Design, Second Edition, United states of America, John Wiley \&Sons 1997..p73

15. Srilakshmi.A, Koteswararao.N.V, Srinivasarao.D, Recent Advances in

Intelligent Computational Systems (RAICS),Parametric analysis of

Figure eight shaped slot antenna 2011 IEEE, 2011 , Page(s): $851-$ 855 